\title{
Towards an objective assessment of energy efficiency in heritage buildings
}

\author{
V. Ingram ${ }^{1, *}$, P.F.G.Banfill ${ }^{1}$, C.Kennedy ${ }^{2}$ \\ ${ }^{1}$ Heriot-Watt University, Edinburgh, UK \\ ${ }^{2}$ Historic Scotland, Edinburgh, UK \\ *Corresponding author. Tel: +44 1314514637, E-mail: vgi1@hw.ac.uk
}

\begin{abstract}
All dwellings in the UK are required to have an Energy Performance Certificate (EPC) when sold or let, giving potential owners or tenants information on the cost and associated $\mathrm{CO}_{2}$ emissions of heat and power. The Scottish traditional construction of solid stone walls tends to get unfavourable EPC ratings, leading to a perception that 'old is cold': this paper uses alternative calculation methods to question that perception.

The difference in results from steady-state and dynamic energy assessment methods is investigated for a dwelling with high thermal mass. The study focuses on modelled data and concludes that SAP 2009's monthly assessment estimates lower energy use and therefore gives a more favourable EPC rating than the annually based RdSAP 2005; and further that the application of dynamic simulation models may not be the optimum solution to further understanding energy efficiency of this type of dwelling.
\end{abstract}

Keywords: Energy assessment, Behaviour, Thermal mass, Heritage, Dynamic simulation

\section{Purpose of the research}

\subsection{Introduction}

In Scotland, nearly 20\% of the housing stock was built pre-1919[1], and is considered to be of traditional construction. For the purpose of this research, traditional construction is defined as a dwelling with solid stone walls, although it is worth noting that other construction types were used in this pre-1919 era. For many people there is a perception that these types of dwellings are draughty, cold, and expensive to heat. The introduction of EPCs has tended to affirm that perception, with very low ratings for larger dwellings of this construction. However, work by Historic Scotland, the Government department responsible for the historic environment in Scotland, and others, is starting to question this perception. The perception of "old is cold" can be viewed from many angles, as different variables are important to different groups. For example, a government may look at statistics provided via EPCs, a homeowner may consider fuel bills, a tenant whose rent includes bills (and therefore has little concept of the cost of heating) may purely consider the temperature of surfaces (stone walls feel cooler to the touch) or the feel of draughts. If the relationship between thermal inertia, occupancy and energy use can be better understood, energy modelling can be instrumental in changing people's perceptions of energy use within dwellings, better educating them towards reducing energy use.

This research sets out to compare three energy assessment methods for a case study dwelling - a traditional mid-terrace, mid-floor, tenement flat in Edinburgh. It aimed to investigate how well the models predict energy demand, and how they assimilate the high levels of thermal mass seen in solid wall construction throughout the model, including feedbacks.

\section{Approach and methodology}

\subsection{Dwelling types}

The research aimed to be relevant to as many stakeholders as possible. Therefore, the most recent Scottish House Condition Survey (SHCS) report data from 2009 is used to assess the Scottish housing profile. Direct comparison can be made between just the pre-1919 dwellings 
using detailed data - Table 1 shows the dwelling types and which are most prevalent within the age band, hence the choice of tenement flat as the case study dwelling, being a considerable proportion of the pre-1919 housing stock[1].

Table 1. Housing split across pre-1919 housing stock in Scotland[1].

\begin{tabular}{|c|c|c|}
\hline House type & Number & Percentage of pre-1919 stock \\
\hline Detached & 109,000 & 24 \\
\hline Semi-detached & 68,000 & 15 \\
\hline Mid-terrace & 53,000 & 12 \\
\hline Tenement flat & 180,000 & 40 \\
\hline \multirow[t]{2}{*}{ Other flats } & 39,000 & 9 \\
\hline & 449,000 & 100 \\
\hline
\end{tabular}

\subsection{Models}

There are a number of building performance simulation models available globally and in the UK. To maintain relevance for the widest audience, the project uses models that are accredited in the UK to produce energy performance certificates and carry out Building Standards compliance checks.

Standard Assessment Procedure (SAP)[2] is used for new-build dwellings, Reduced Data SAP (RdSAP) is used for existing dwellings[3], and IES $<\mathrm{VE}>$ is a dynamic simulation software used for non-domestic buildings. The background to each model used is explained, with a summary of how the model was used and the assumptions made.

\subsubsection{SAP 2009}

The primary purpose of energy assessment in the UK is producing Energy Performance Certificates (EPCs) for both domestic and non-domestic buildings, at the point of sale or rent.

Standard Assessment Procedure (SAP) began in 1993, with a number of both major and minor alterations to the methodology since[2]. The largest overhaul was following the introduction of the Energy Performance of Buildings Directive (EPBD) in 2002: an update to SAP was needed to ensure it was consistent with energy assessment methods across the EU.

The latest update to SAP came in April 2010, as the Government released SAP 2009, v9.90, to be used from October 2010[2]. This new model has updated carbon emission factors, fuel prices, climate information, and also now includes space cooling. The biggest difference to v9.90 is that it has moved from an annual calculation to a monthly calculation. SAP uses a steady-state calculation, in that it assumes that variables are constant within each time step, implying that the method has become more detailed and aims to be more accurate, however, it does not include feedbacks within the system.

While the technical guide and calculation methodology for SAP are open to anyone to view and download, the majority of software providers allow access to their SAP programmes only to qualified assessors. A minority allow unlimited or academic access. The defined SAP methodology[2] has therefore been put into a bespoke spreadsheet model to enable detailed examination of the calculations and relationship between variables. 


\subsubsection{RdSAP 2005[3]}

The most significant change to SAP has been the introduction of RdSAP in 2007, used solely for predicting the energy demand in existing dwellings. It does this by providing a database of information to be used in the calculation where an assessor finds information unobtainable (such as wall construction, thickness, U-values) as the dwelling is already built. For dwellings built in the $20^{\text {th }}$ century the system is relatively fair, creating age bands of dwellings. For example all housing post-1984 will have the same characteristics. However for dwellings built prior to 1919, the focus of this research, there is a single age band, which may lead to unrepresentative information being used in the model, affecting the modelling result[4].

Figure 1 shows that the frequency of updates to SAP and RdSAP has increased, but also shows that the model used for RdSAP is consistently behind SAP which is used for newbuilds. Since October 2010, new-build dwellings are required to use SAP 2009, v9.90, whilst existing buildings continue to use SAP 2005, v9.83, using the previous set of carbon factors and out of date fuel prices.

\begin{tabular}{|c|c|c|c|c|c|c|c|c|c|c|c|c|}
\hline \multicolumn{13}{|l|}{$\begin{array}{l}\text { SAP } \\
\text { Introduced }\end{array}$} \\
\hline \multicolumn{13}{|c|}{ Ratings changed } \\
\hline \multicolumn{13}{|l|}{ SAP 2001} \\
\hline \multirow[t]{2}{*}{ SAP 2005} & & & & & & & 2005 & 9.80 & & & & \\
\hline & & & & & & & & & & \multicolumn{2}{|c|}{2005 v9.81 } & \\
\hline SAP 2009 & & & & & & & & & & & & 2009 v9.90 \\
\hline \multicolumn{13}{|l|}{ RdSAP } \\
\hline Introduced & & & & & & & & & \multicolumn{2}{|c|}{2005 v9.80 } & & \\
\hline Updated & & & & & & & & & & & \multicolumn{2}{|c|}{2005 v9.82 } \\
\hline Updated & & & & & & & & & & & 2005 & 9.83 \\
\hline
\end{tabular}

Fig 1. Changes to SAP since its introduction in 1993[2]

Similarly to the method used for SAP, the defined RdSAP methodology[3] has been put into a bespoke spreadsheet model, enabling in-depth examination of the calculations and relationships between variables. This method also allows direct comparison between entering known values and those from the construction database.

\subsubsection{Dynamic Simulation Models}

There may be scope for non-domestic models, their principles or methods to be included within domestic models, or to replace them. In addition to the standard domestic (SAP and RdSAP) and non-domestic methods, the UK National Calculation Methodology (NCM) includes Dynamic Simulation Models (DSMs). These DSMs look at both high spatial resolution as well as high temporal resolution to model the changes that occur over time using fundamental mathematics of the heat transfer processes that occur both inside and around a building.

As well as the basic heat gains and losses calculations, DSMs also include convection, heat transfer by air movement, thermal radiation transmitted by surfaces, solar transmission, and absorption and reflection by any glazing. The heat gains utilised are both sensible heat (the 
temperature change in the air of the room) and latent heat (the change in humidity in the room). Dynamic models require the building to be divided into multiple zones, and use much more detailed weather data than in SAP and RdSAP, from the Chartered Institute of Building Services Engineers (CIBSE)[5].

In the UK, there are two DSMs accredited to produce EPCs for non-domestic buildings: this research uses IES $<\mathrm{VE}>$, or Virtual Environment. IES originated from academic research, but became commercial in 1994 with a user-friendly interface[6], and by using the same userinterface as professionals in the construction sector it is believed that the conclusions of this research will be accessible to a larger number of readers.

\subsection{Occupancy}

The SHCS provides information on the demographics of occupants in dwelling types within the pre-1919 age band of housing[1]. Using this data three occupancy profiles were produced, summarised in Table 2. These are expanded upon using studies by the Energy Saving Trust and reasonable assumptions (by the authors), to provide a list of appliances used in each occupancy profile, and assumptions are made with respect to use of heating and behaviour towards ventilation and heating where possible within the models used.

Table 2. Summary of occupancy profiles to be assumed in the research.

\begin{tabular}{lccc}
\hline & \multicolumn{3}{c}{ Occupancy Profile } \\
\hline Description & 1 & 2 & 3 \\
Number of adults & Single adult & Small family & Older smaller \\
Age of adults & 1 & 2 & 2 \\
Number of children & $16-34$ & $45-54$ & $70-80$ \\
Age of children & 0 & 2 & 0 \\
\hline
\end{tabular}

To assess the effect of occupancy on energy use in dwellings of traditional construction, IES $<$ VE $>$ is used, as neither SAP or RdSAP include appliance use in energy consumption calculations. During the initial model runs when comparing IES $<\mathrm{VE}>$ and the two SAP methods, occupancy profiles from the NCM are used, to ensure that as many variables as possible are the same in the DSM as in SAP 2009 and RdSAP 2005. However, to assess occupancy effects, the profiles from Table 2 are used, with tailor-made equipment, lighting, appliances and occupant activity profiles defined within the DSM.

\subsection{Data Collection}

For any type of building performance simulation, certain basic details are required, such as dimensions, heating system information, and constructions. Depending on the model used and therefore level of information required, additional details are sometimes required. A complete data set for the Case Study dwelling was collected by the author, through consulting with architectural plans and discussions with the homeowner/occupant. Typically, however, assessments of existing dwellings are done by site visits and physical measurements made. For this case study, architectural plans were available following work carried out on the flat in 1992.

By collecting sufficient data for a DSM, certain variables are known in greater detail than are needed for SAP and certainly for RdSAP. The methodology within RdSAP requires that certain variables are entered as defaults, and others are entered in more detail. 


\section{Results}

\subsection{SAP 2009 vs RdSAP 2005}

When comparing the two domestic energy assessment methods, the variables that differ greatly are solar gains, fuel for space heating, and $\mathrm{CO}_{2}$ emissions from space heating (see Table 3). The factors contributing to these variables can be traced back through the calculation to further understand the differences.

\subsubsection{Solar gains}

The method used to calculate solar gains in RdSAP 2005 uses a UK average vertical solar flux for the year, applied to each area of glazing. The SAP 2009 method is far more detailed, doing a monthly calculation using the mean global solar radiation on the horizontal for latitude $53.4^{\circ}$ (approximately Manchester, UK), then calculating the vertical solar flux from that using orientation, and then calculating solar gain, again applied to each area of glazing.

\subsubsection{Fuel for space heating}

The fuel used for space heating is a factor of the heating system efficiency (identical in both SAP 2009 and RdSAP 2005 and therefore negligible) and the heating requirement - the $\mathrm{kWh} /$ year needed to heat the dwelling to the required internal temperature. This heating requirement is where the difference between the methods lies.

In SAP 2009, the heating requirement is a factor of the Heat Loss Coefficient, the total internal gains, the average external temperature, and the average internal temperature. In RdSAP 2005 the heating requirement is a factor of just the internal gains and the Heat Loss Coefficient. The SAP 2009 calculation is therefore more detailed and is also monthly. In both methods, the solar gains are a direct factor towards calculating heating demand, so any errors or differences in calculating solar gains will feed through and enhance the differences in fuel used for space heating.

\subsection{3. $\mathrm{CO}_{2}$ emissions for space heating}

These are a direct function of the fuel used for space heating, and will always be different between models where the fuel demand is different. Additionally, the $\mathrm{CO}_{2}$ emissions are calculated using emission factors $\left(\mathrm{kgCO}_{2} / \mathrm{kWh}\right)$ which were updated in 2009 and for mains gas are now $2 \%$ higher.

\subsection{SAP 2009 vS IES $<V E>$}

The results that can be analysed from IES $<\mathrm{VE}>$ are similar to those from SAP 2009, as they are both in monthly formats. However, IES $<\mathrm{VE}>$ allows the user to go into more detail down to hourly level, and view in graphical format the energy use, emissions, and internal variables such as temperature.

Table 3 compares the key variables from SAP 2009 with those from IES $<$ VE $>$. IES includes equipment in its total electricity figures while SAP and RdSAP do not, therefore only electricity for lighting is shown here for more accurate comparison.

It is obvious from Table 3 that IES $<\mathrm{VE}>$ is the most onerous method of assessing energy and emissions from this tenement flat. Additional analysis may assess whether the reason is inaccuracies in the database's default values, the calculation method, or inconsistencies in data entry across all three models due to the inputs required. 
Table 3. Summary of key variables across the three models.

\begin{tabular}{|c|c|c|c|c|}
\hline Variable & Units & RdSAP 2005 & SAP 2009 & IES $<$ VE $>$ \\
\hline Space heating demand & kWh/year & 6813 & 3366 & 13,067 \\
\hline DHW demand & kWh/year & 2791 & 2371 & 161 \\
\hline Lighting electricity demand & kWh/year & 317 & 298 & 1457 \\
\hline Total energy demand & kWh/year & 10,052 & 6165 & 15,900 \\
\hline Space heating emissions & $\mathrm{kgCO}_{2} /$ year & 1322 & 666 & 2566 \\
\hline DHW emissions & $\mathrm{kgCO}_{2} /$ year & 542 & 469 & 2560 \\
\hline Lighting emissions & $\mathrm{kgCO}_{2} /$ year & 134 & 154 & 615 \\
\hline Total emissions & $\mathrm{kgCO}_{2} /$ year & 2052 & 1357 & 3674 \\
\hline SAP rating & n/a & 78 & 87 & $*$ \\
\hline EPC rating & $\mathrm{n} / \mathrm{a}$ & $\mathrm{C}$ & B & * \\
\hline
\end{tabular}

Notes: $*=$ Not calculated within IES $<\mathrm{VE}>$ for this dwelling.

\subsection{Occupancy effects}

Both SAP 2009 and RdSAP 2005 use a standard assumption of the number of occupants in a dwelling. The equations used differ but both are factors of the total floor area. In this case study the results are the same, assuming occupancy of 2.13 people, while in reality the flat is home to 2 adults. Consequently, in this case study it can be suggested that the energy requirements for domestic hot water, heating and lighting may not differ wildly when using the exact figure of 2 people. However, as mentioned in 3.2, SAP does not include the energy for equipment and appliances. By including these, it is suggested that the total energy demand and total emissions will both increase. This case study has two bedrooms, and could potentially also house two young children in the second bedroom, increasing the equipment use with additional televisions etc, but also increasing all other loads within the dwelling, as more showers are taken, more food is prepared, and more rooms require heating and lighting.

\section{Discussion}

Energy assessment in the domestic sector has one main purpose - the production of EPCs. With new-build dwellings, energy assessment methods can be used during the design phase to reach a particular level of design and $\mathrm{CO}_{2}$ and energy savings as required by planning conditions, by suggesting constructions, insulation levels, and low or zero carbon technologies. For existing dwellings, energy assessment can also be used for this, but if the assessment is inaccurate, it may result in inadequate, deficient or inefficient retrofits.

While the EPC system is designed to be standardised across the UK, with standardised occupancy and location information used (in RdSAP at least), it only serves its purpose truly for sale and rentals, as it informs the new occupier of suggested costs. The methodology as it is cannot identify areas of high energy use or optimum areas for retrofit for a particular occupancy. For example, in a large house with occupancy profile 3, greater emissions savings may be made with retrofit options that favour reduced heating thereby reducing bills and raising quality of life as the occupants regain use of rooms previously cut off as 'too cold'. In a small flat with occupancy profile 2 where appliance and equipment use is heavy, it may be wiser to reduce electrical demand through efficient appliances, or introduce renewable electricity supply. 
In terms of the human impact on energy assessment and on the occupant's energy use the second biggest factor is the way the assessor carries out the data collection and RdSAP calculation. There are a number of areas within RdSAP where detailed information can be found if the assessor has the time or inclination to find it, but due to time constraints on a project they may use more default information from the database than is ideal. While assessors undergo training and examination, there is currently no quality control stipulated in the Building Standards for Scotland [7]. Only if an assessor is accredited through an Englishbased company will they undergo recurrent checks on their assessments. It is suggested that these assessor errors could be significant, and further research on this is in progress.

As outlined earlier, energy assessment needs to be as accurate as possible for informed decision making, but there are varying levels of complexity of models, and balance is needed between simplicity and complexity. DSMs use detailed input data and are time intensive, whereas simplified steady state methods use a less accurate approach in a faster time. It remains to be seen whether a single optimal method can be found that combines improved levels of detail with short timescales. To combine accuracy and speed, a statistical approach could be used to define polynomial functions from the DSM to provide statistical methods that in essence are a simplified dynamic approach [8,9]. Table 4 outlines the main differences between the types of model looked at within this research.

Table 4. Summary of main variables and differences between assessment methods

\begin{tabular}{lccc}
\hline UK Accredited for: & SAP & RdSAP & Dynamic \\
\hline Construction details & Exact, from plans & $\begin{array}{c}\text { Database unless } \\
\text { known }\end{array}$ & $\begin{array}{c}\text { Don-domestic } \\
\text { knowe unless } \\
\text { known }\end{array}$ \\
\hline Thermal Mass & Limited & $\boldsymbol{x}$ & $\checkmark$ \\
\hline Include heat gains & $\boldsymbol{x}$ & $\boldsymbol{x}$ & $\checkmark$ \\
\hline $\begin{array}{l}\text { Overheating risk } \\
\text { as standard) }\end{array}$ & $\boldsymbol{x}$ & Annual & $\checkmark$ \\
\hline Climate variables & Monthly & $\begin{array}{c}\text { 1-2hrs } \\
\text { site visit }\end{array}$ & $\begin{array}{c}\text { Hourly } \\
+ \text { site visit }\end{array}$ \\
\hline Time to assess & $1-2 \mathrm{hrs}$ & $£ £$ & $£ £ £$ upwards \\
\hline Cost to assess & $£ £$ & &
\end{tabular}

RdSAP and SAP both require a number of simplifications in the data input. In both methods, a default database U-value for solid sandstone walls was used; however work is ongoing at Historic Scotland to measure U-values in-situ. It may be possible in future to use measured Uvalues to better represent a particular dwelling's heat loss.

The research in this paper could be compared to real energy bills in an attempt to validate the analysis, but there will still be inconsistencies, as so many aspects of the SAP and RdSAP methodologies are standardised and fail to include equipment and appliances. An energy assessment was carried out on this property in 2009, but comparisons between the assessment here and the EPC are difficult for three main reasons: the EPC assessor assumed no flats on the ground floor, substantially increasing the area of heat loss; the EPC assessor used a different floor area $\left(75 \mathrm{~m}^{2}\right.$ to the $65 \mathrm{~m}^{2}$ used from plans); a new boiler was installed in 2010 , improving the space and water heating efficiency and therefore energy demand. The first two points here are indicative of the human error aspect explored in Section 4. 
Rapid changes within the construction industry and Building Standards equally past, present and future, combined with updates to the energy assessment methodology, mean that energy assessment stakeholders work in a rapidly changing arena. Updates to Building Standards are expected in 2013 and beyond, and changes in the EPBD cannot be ruled out. Future Standards may require different things of existing buildings, and energy assessment may have a different purpose. Therefore, while the outcomes of this research are relevant in 2011, their relevance in the future cannot be predicted.

\section{Conclusions}

It can be seen here that the models disagree on key variables. Where SAP 2009 and RdSAP agree quite well as to the energy required for DHW and lighting, IES predicts a far higher lighting demand, but a much lower DHW demand. Similarly to the lighting, IES predicts far higher space heating demand than the domestic models. If comparing just the domestic models, SAP 2009 predicts lower energy use for all variables than RdSAP 2005. Further work will be carried out into the variations in energy demand predicted by the models used.

This work shows there is still potential for improving energy assessment, and the complexity of precise energy assessment does not necessarily lead to accurate energy assessment.

\section{References}

[1] SHCS. 2010. Scottish House Condition Survey: Key findings for 2009. http://www.scotland.gov.uk/Topics/Statistics/SHCS/Downloads Accessed 14 December 2010

[2] BRE, 2010a. The Government's Standard Assessment Procedure for Energy Rating of Dwellings. 2009 Edition. Available at http://www.bre.co.uk/sap2009/page.jsp?id=1642 Accessed 3 May 2010

[3] BRE. 2009. Standard Assessment Procedure 2005 v9.83. Available at www.bre.co.uk/sap2005 Accessed 12 March 2010

[4] Barnham, B., Heath, N., Pearson, G. 2008. Energy modelling analysis of a traditionally built Scottish tenement flat. Edinburgh, Changeworks

[5] IES. 2009. ApacheSim Calculation Methods <Virtual Environment> 5.9. Integrated Environmental Solutions Limited

[6] IES. 2010. About Us [online content]. Available at http://www.iesve.com/About-us Accessed 14 December 2010

[7] Hughes, A.M. 2010. Discussion on QA/Audit process for Scottish energy assessments. [Telephone conversation] (Personal communication, 05 May 2010)

[8] Caldera, M., Corgnati, S.P., Filippi, M. 2008. Energy demand for space heating through a statistical approach: application to residential buildings. Energy \& Buildings 40(11) pp1972-1983

[9] Jaffal, I., Inard, C., Ghiaus, C. 2009. Fast method to predict building heating demand based on the design of experiments. Energy \& Buildings 41(6) pp669-677. 